\title{
Associations of lead biomarkers with renal function in Korean lead workers
}

\author{
V M Weaver, B-K Lee, K-D Ahn, G-S Lee, A C Todd, W F Stewart, J Wen, D J Simon, \\ P J Parsons, B S Schwartz
}

Occup Environ Med 2003;60:55 1-562

See end of article for authors' affiliations

Correspondence to: Dr B-K Lee, Institute of Industrial Medicine,

Soonchunhyang University, 23-20 Bongmyung-Dong,

Chonan, Choongnam

330-100, Korea;

leebkk@asan.sch.ac.kr

Accepted

5 November 2002

\begin{abstract}
Aims: To compare associations of lead biomarkers with renal function in current and former lead workers.

Methods: Cross sectional analysis of first year results from a longitudinal study of 803 lead workers and 135 controls in South Korea. Clinical renal function was assessed by blood urea nitrogen (BUN), serum creatinine, and measured and calculated creatinine clearance. Urinary N-acetyl- $\beta$-Dglucosaminidase (NAG) and retinol-binding protein were also measured.

Results: Mean (SD) tibia lead, blood lead, and DMSA chelatable lead levels in lead workers were $37.2(40.4) \mathrm{\mu g} / \mathrm{g}$ bone mineral, 32.0 (15.0) $\mathrm{\mu g} / \mathrm{dl}$, and 767.8 (862.1) $\mathrm{\mu g} / \mathrm{g}$ creatinine, respectively. Higher lead measures were associated with worse renal function in 16/42 models. When influential outliers were removed, higher lead measures remained associated with worse renal function in nine models. An additional five associations were in the opposite direction. Effect modification by age was observed. In 3/16 models, associations between higher lead measures and worse clinical renal function in participants in the oldest age tertile were significantly different from associations in those in the youngest age tertile which were in the opposite direction. Mean urinary cadmium (CdU) was $1.1 \mu \mathrm{g} / \mathrm{g}$ creatinine $(n=191)$. Higher CdU levels were associated with higher NAG.

Conclusions: These data suggest that lead has an adverse effect on renal function in the moderate dose range, particularly in older workers. Associations between higher lead measures and lower BUN and serum creatinine and higher creatinine clearances may represent lead induced hyperfiltration. Environmental cadmium may also have an adverse renal impact, at least on NAG.
\end{abstract}

$\mathrm{S}$ everal lines of evidence implicate high level lead exposure as a cause of chronic renal failure. These include mortality studies of lead workers, ${ }^{1}$ historical occupational experience, ${ }^{2}$ and long term follow up of severely lead poisoned children. ${ }^{3}$ Research has also revealed increased lead body burdens in participants selected by specific diseases such as renal insufficiency, gout, and hypertension, particularly when they coexist in the same patient. ${ }^{4}$

Studies of low level lead exposure have also reported lead associations with adverse renal outcomes. Two large cross sectional general population studies (with $744^{5}$ and $1981^{6}$ participants) revealed inverse associations between creatinine clearance and blood lead. Analysis of longitudinal serum creatinine and blood lead data from a subset of the US population

\section{Main messages}

- Higher levels of lead exposure, dose, and haematological effect measures were associated with worse clinical renal function and higher levels of NAG and RBP.

- Associations in the opposite direction (higher lead measures with lower BUN/serum creatinine and higher creatinine clearances) were also found, particularly in analyses of current workers only.

- Age was observed to modify relations between lead measures and renal function. Higher lead exposure and dose were associated with worse renal function in older workers, but with lower BUN and serum creatinine in young workers.

- Urinary cadmium levels, in a range consistent with environmental exposure, were associated with higher NAG levels. mentioned above $e^{5}$ also revealed a greater rate of serum creatinine increase in the highest lead exposure quartile compared to the lowest. ${ }^{7}$ Furthermore, studies focusing on patients with renal insufficiency have shown stabilisation and, in some cases, improvement of renal function after therapeutic calcium disodium ethylenediamine tetraacetic acid (EDTA) chelation of relatively low lead body burdens that are generally not chelated ( $>80-150$ (depending on study), but $<600 \mu \mathrm{g}$ lead excreted in 72 hours after intravenous administration of 1 g EDTA). ${ }^{8}$

However, recent occupational studies have yielded inconsistent results. Lead exposure was generally moderate (mean or median blood lead $\sim 30-55 \mu \mathrm{g} / \mathrm{dl}$ ), although some studies reported only ranges and included substantial numbers of

\section{Policy implications}

- Lead has an adverse impact on renal function, particularly in older workers, and may initially influence renal function through hyperfiltration.

- Cadmium exposure should be measured in studies of the renal effects of lead exposure.

\footnotetext{
Abbreviations: ALAP, aminolaevulinic acid in plasma; BUN, blood urea nitrogen; $\mathrm{BMI}$, body mass index; $\mathrm{CdU}$, urinary cadmium; $\mathrm{CV}$, coefficient of variation; DM, diabetes mellitus; DMSA, dimercaptosuccinic acid; EBE, early biological effect; EDTA, calcium disodium ethylenediamine tetraacetic acid; $\mathrm{Hb}$, haemoglobin; LD, limit of detection; NAG, $\mathrm{N}$-acetyl- $\beta$-D-glucosaminidase; PBS, phosphate buffered saline; RBP, retinol-binding protein; SD, standard deviation; ZPP, zinc protoporpyhrin
} 
workers with levels over $80 \mu \mathrm{g} / \mathrm{dl}$. Several studies noted associations between lead exposure (assessed by blood lead, years of exposure, and/or zinc protoporpyhrin (ZPP)) and clinical renal outcomes (blood urea nitrogen (BUN), serum creatinine, and/or creatinine clearance) and/or early biological effect (EBE) markers, such as $\mathrm{N}$-acetyl- $\beta$-D-glucosaminidase (NAG) and retinol-binding protein (RBP). ${ }^{10-16}$ These studies had smaller sample sizes than the environmental studies (median sample size $=218$ ) and statistical analysis was more limited, consisting of correlations or simple linear regression in half with the other half controlling for age and, in one, ${ }^{16}$ age, height, and weight. In contrast, other occupational studies have either found no significant difference in renal measures in lead workers compared to controls and/or few to no associations when continuous lead measures were analysed. ${ }^{17-20}$ Median sample size of these studies was 112; covariates controlled for were similar to the occupational studies in which associations were reported. Exposure assessment included tibia lead in one of these studies. ${ }^{20}$

A number of factors may be contributing to these discrepant results, including sample size, healthy worker effect, insensitivity of renal outcomes, and limited exposure assessment. Environmental level of cadmium, although not routinely measured in most lead studies, has been shown to be an important confounder in some populations, particularly for lead associations with NAG. ${ }^{1821} 22$ Finally, some researchers have observed associations between higher creatinine clearance and higher lead exposure or dose measures. ${ }^{21}{ }^{23}$ Significant findings could be obscured if associations in opposite directions are present in different segments of the study population.

We report a cross sectional analysis of renal outcomes data from the first year of a three year longitudinal study of the health effects of inorganic lead exposure. The study included 803 Korean lead workers and 135 controls. Exposure assessment included blood lead, tibia lead, and four hour dimercaptosuccinic acid (DMSA) chelatable lead measures as well as job duration. Urinary cadmium (CdU) was measured on a $24 \%$ subset of the lead exposed workers. Renal outcomes, ranging from clinical measures to EBE markers, were analysed. To our knowledge, this is the largest study of lead workers with this type of detailed exposure and outcome assessment reported to date.

\section{MATERIALS AND METHODS \\ Study overview and design}

This report focuses on data obtained from 803 current and former lead workers and 135 controls from the first of three annual visits in a longitudinal study of the neurobehavioural, peripheral nervous system, renal, haematopoietic, and blood pressure effects of inorganic lead exposure. Participants were enrolled between 24 October 1997 and 19 August 1999. All participants provided written, informed consent. The study protocol was approved by Institutional Review Boards at the Soonchunhyang University School of Medicine and the Johns Hopkins University Bloomberg School of Public Health. Participation in the study was voluntary, and workers were paid approximately $\$ 30$ for their time and effort.

\section{Study population}

Lead workers were recruited from 26 different facilities including lead battery, lead oxide, lead crystal, radiator manufacture, and secondary lead smelting. ${ }^{24}$ Workers were designated as lead workers based on the potential for exposure to lead in the manufacturing process. Participation rates generally exceeded $85 \%$ in all plants except for four battery manufacture facilities where, because of the economic challenges that confronted South Korea during recruitment for this study, rates ranged from $17 \%$ to $58 \%$. Ninety four former lead workers also participated. This number is higher than in prior publications from this study ${ }^{24}$ because it includes 24 retired workers (three of whom had been medically removed from exposure because of high lead levels) and 70 former workers who left lead industry employment as a result of a plant shut-down because of the adverse economic conditions. Ninety eight controls were recruited from an air conditioner assembly plant that did not use lead or other heavy metals, and 37 controls were wage workers of Soonchunhyang University. No medical exclusion criteria (for example, abnormal blood pressure, renal disease) were applied for any study participants. Study participants were not currently occupationally exposed to other known renal toxicants. CdU was obtained to document lack of occupational exposure to this renal toxicant and for analysis of environmental cadmium associations.

\section{Data collection}

Data collection was completed either at the Institute of Industrial Medicine in Chonan or at the study plants using previously reported methods. ${ }^{24}$ Data and biological specimens collected included: a standardised questionnaire on demographics, medical history, and occupational history; blood pressure (systolic and 5th Korotkoff diastolic), measured with a Hawksley random zero sphygmomanometer ${ }^{25}$; height and weight measurement; a blood specimen (for blood lead, BUN, serum creatinine, haemoglobin ( $\mathrm{Hb}), \mathrm{ZPP}$, and aminolaevulinic acid in plasma (ALAP)) and a spot urine sample (for $\mathrm{RBP}, \mathrm{NAG}$, and $\mathrm{CdU}$ ), both of which were stored at $-70^{\circ} \mathrm{C}$ until analysed; and tibia lead concentration. A four hour urine collection after oral administration of $10 \mathrm{mg} / \mathrm{kg}$ DMSA, which was also used for measured creatinine clearance assessment, was obtained in lead workers only.

\section{Laboratory methods}

Blood lead was measured with a Hitachi 8100 Zeeman background corrected atomic absorption spectrophotometer (Hitachi Ltd Instruments, Tokyo, Japan) with the standard addition method of the National Institute of Occupational Safety and Health ${ }^{26}$ at the Institute of Industrial Medicine, a certified reference laboratory for lead in South Korea. Tibia lead was assessed with a 30 minute measurement at the left mid-tibia shaft using ${ }^{109} \mathrm{Cd} \mathrm{K}$-shell $x$ ray fluorescence as previously described. ${ }^{27-29}$ All point estimates, including negative values, were retained in the statistical analyses in order to minimise bias and avoid censoring of data. ${ }^{30}$ Four hour urinary lead excretion after oral administration of $10 \mathrm{mg} / \mathrm{kg}$ DMSA was used to measure DMSA chelatable lead and creatinine clearance in lead exposed participants only (787 participants completed the urine collection). Urine lead levels were measured in the laboratories of the Wadsworth Center at the New York State Department of Health (Albany, NY, USA) by electrothermal atomic absorption spectrometry with Zeeman background correction (Perkin-Elmer Model 4100ZL, Norwalk, CT, USA). ${ }^{31}$ The Wadsworth Center participates in the NY State proficiency testing programme for urine lead and the external interlaboratory comparison programme for toxic substances of the Centre de Toxicologie, Direction de la toxicologie humaine, Institut national de santé publique du Québec.

CdU was measured by electrothermal atomic absorption spectroscopy with Zeeman background correction ${ }^{32}$ at Pacific Toxicology Laboratories (Woodland Hills, CA, USA) ( $\mathrm{n}=152$ samples) or Quest Diagnostics (Teterboro, NJ, USA) ( $\mathrm{n}=39$ samples). Both laboratories participate in the interlaboratory comparison programme for toxic substances of the Centre de Toxicologie, Direction de la toxicologie humaine, Institut national de santé publique du Québec. Because of budgetary constraints, CdU measurements were performed on a subset of 191 lead exposed workers. In order to maximise our ability to determine whether cadmium was a confounder, samples 
Table 1 Demographic, exposure, and selected health outcome measures of study participants

\begin{tabular}{|c|c|c|}
\hline Characteristic & Lead exposed participants $(n=803)$ & Controls $(n=135)$ \\
\hline Age, years, mean (SD) [range] ${ }^{*}$ & $40.4(10.1)[17.8-64.8]$ & $34.5(9.1)[22.1-60.2]$ \\
\hline \multicolumn{3}{|l|}{ Sex, $n(\%)^{*}$} \\
\hline Male & $639(79.6)$ & $124(91.9)$ \\
\hline Female & $164(20.4)$ & $11(8.1)$ \\
\hline $\mathrm{BMI}, \mathrm{kg} / \mathrm{m}^{2}$, mean (SD) [range] ${ }^{*}$ & $23.0(3.0)[15.7-34.2]$ & $23.7(2.8)[18.5-30.1]$ \\
\hline Regular analgesic use, $\mathrm{n}(\%)$ & $16(2.0)$ & $1(0.8)$ \\
\hline Diabetes, $\mathrm{n}(\%)$ & $6(0.8)$ & $2(1.5)$ \\
\hline Hypertension, $\mathrm{n}(\%)$ & $58(7.2)$ & $11(8.2)$ \\
\hline Blood lead, $\mu \mathrm{g} / \mathrm{dl}$, mean (SD) [range]* & $32.0(15.0)[4.3-85.7]$ & $5.3(1.8)[2-10]$ \\
\hline Tibia lead, $\mu \mathrm{g} \mathrm{Pb} / \mathrm{g}$ bone mineral, mean (SD) [range]* & $37.2(40.4)[-7.4-337.6]$ & $5.8(7.0)[-10.9-26.6]$ \\
\hline DMSA chelatable lead, $\mu \mathrm{g} \mathrm{Pb} / \mathrm{g}$ creatinine, mean (SD) [range] & $767.8(862.1)[23.8-8974.6]$ & NA $\ddagger$ \\
\hline Lead job duration, years, mean (SD) [range] & $8.2(6.5)[<1-36.2]$ & NA \\
\hline Urinary cadmium, $\mu \mathrm{g} / \mathrm{g}$ creatinine, mean (SD) [range]§ & $1.1(0.78)[0.2-7.39]$ & NA \\
\hline BUN, $\mathrm{mg} / \mathrm{dl}$, mean (SD) [range] ${ }^{*}$ & $14.4(3.7)[6-32.2]$ & $13.1(2.9)[5.9-21.8]$ \\
\hline Serum creatinine, $\mathrm{mg} / \mathrm{dl}$, mean (SD) [range] & $0.90(0.16)[0.48-2.5]$ & $0.91(0.10)[0.63-1.25]$ \\
\hline Measured creatinine clearance, $\mathrm{ml} / \mathrm{min}$, mean (SD) [range] & $114.7(33.6)[11.8-338.9]$ & NA $\ddagger$ \\
\hline Calculated creatinine clearance, $\mathrm{ml} / \mathrm{min}$, mean (SD) [range] & $94.7(20.7)[41.1-184.5]$ & $108.4(19.4)[71.2-157.7]$ \\
\hline $\mathrm{NAG}, \mu \mathrm{mol} / \mathrm{h} / \mathrm{g}$ creatinine, mean (SD) [range] & $215.3(188.5)[13.8-2577.0]$ & 174.5 (115.6) [38.1-938.9] \\
\hline RBP, $\mu \mathrm{g} / \mathrm{g}$ creatinine, mean (SD) [range] & 63.6 (190.6) [5.2-4658.7] & $46.2(44.3)[5.4-394.0]$ \\
\hline
\end{tabular}

†Data missing for 20 controls.

†NA indicates not applicable. DMSA chelation with subsequent four hour urine collection performed only in exposed participants ( $\mathrm{n}=787$ ).

$\S n=191$.

IRange 0.2-3.9 with one outlier of 7.3

${ }^{*} \mathrm{p}<0.05$

were selected by renal function and cumulative lead exposure as follows: 19 were from workers with consistent evidence of renal damage (two or more adversely affected renal outcomes), 10 were randomly selected from the lowest quartile of tibia lead, 10 were randomly selected from the highest quartile of tibia lead, and 152 were randomly selected from the entire range of tibia lead. CdU levels below the $0.5 \mu \mathrm{g} / \mathrm{l}$ limit of detection ( $\mathrm{LD})(\mathrm{n}=38,19.9 \%)$ were estimated by dividing the LD by the square root of $2 .^{33}$

BUN and serum creatinine were measured via an automatic chemical analyser (Toshiba TBA 40FR Biochemical Analyzer, Tokyo, Japan). The serum creatinine assay used the Jaffe method with an absorbance of $505 \mathrm{~nm}$, and the BUN assay utilised urease and glutamate dehydrogenase. Urine creatinine was measured in spot samples for adjustment of EBE markers and in the four hour sample after DMSA for determination of measured creatinine clearance and adjustment of DMSA chelatable lead levels. The assay was performed using a modification of the Sigma kit (St Louis, MO, USA) assay as previously described..$^{34}$ Measured creatinine clearance was defined as: ([urinary creatinine in $\mathrm{mg} / \mathrm{dl} \times$ urine volume in $\mathrm{ml}] /$ serum creatinine in $\mathrm{mg} / \mathrm{dl}) \times$ collection time in minutes. Calculated creatinine clearance was defined as ([140-age] $\times$ weight in $\mathrm{kg}) /(72 \times$ serum creatinine $)$ for males and the same equation multiplied by 0.85 for females. ${ }^{35}$

In order to determine whether DMSA and/or lead in urine interfered with the creatinine assay, 12 samples were selected, both randomly and by inclusion of the highest DMSA chelatable lead results, and spiked with creatinine standard (Sigma, St Louis, MO, USA). The results were compared with expected values (based on amount of standard added). Pearson's $r$ was 0.998. Linear regression revealed a slope of 0.95 (95\% CI: 0.91 to 0.99 ) and intercept of 5.15 (95\% CI: -0.99 to 11.3 ). The mean coefficient of variation (CV) was $1.5 \%$ for 12 samples $(\mathrm{n}=2$ per sample). The mean (SD) of the differences between observed and expected results was $3.2(2.2)$. Therefore, these data revealed no lead or DMSA interference with the creatinine assay. There was also no evidence that DMSA interfered with creatinine excretion in vivo, as the mean measured four hour creatinine clearances were within the range of normal expected values for both males and females (determined by multiplying published values ${ }^{36}$ for 24 hour creatinine excretion $(\mathrm{mg} / \mathrm{kg})$ by the mean weight of study participants and dividing to adjust for a four hour collection period). The
Spearman rank correlation between measured and calculated creatinine clearance $\left(r_{\mathrm{s}}=0.64\right)$ also indicated no DMSA interference with measured creatinine clearance.

NAG was measured using the PPR NAG Test kit (PPR Diagnostics Ltd, London, UK). This assay uses 2-methoxy-4-(2'nitrovinyl)-phenyl 2 -acetamido-2-deoxy- $\beta$-D-glucopyranoside as the substrate which is hydrolysed by NAG to form 2-methoxy-4-(2'-nitrovinyl)-phenol. ${ }^{37} \quad$ Absorbance was measured at $505 \mathrm{~nm}$ in a UVl spectrophotometer (Spectronic Unicam, Cambridge, UK). Semimicro cuvets ( $1.5 \mathrm{ml}$ ) (Fisher Scientific, Pittsburgh, PA, USA) were utilised so that each assay required $60 \%$ of the suggested reagent volumes. Urine samples were not centrifuged. To evaluate assay reliability, 138 random samples $(14.7 \%)$ were measured in duplicate; mean inter-assay, between day CV was 6.0\% (SD 7.7\%).

RBP was measured using a modification of the method of Topping and colleagues. ${ }^{38}$ Nunc-Immno 96-well polystyrene flat (MaxiSorp surface) microplates (Fisher Scientific, Pittsburgh, PA, USA) were coated by incubating $150 \mu \mathrm{l}$ per well of rabbit antibody to urinary human RBP (Dako Corp., Carpinteria, CA, USA), diluted 3000-fold in $60 \mathrm{mmol}$ carbonate/ bicarbonate buffer, $\mathrm{pH}$ 9.6, for five hours at room temperature. Plates were then washed four times with PBS with $0.1 \%$ Tween 20 , pH 7.5 ( $250 \mu \mathrm{l}$ per well each wash). The plates were then coated with $100 \mu \mathrm{l}$ per well of sample (urine diluted 50- and 100 -fold with PBS with $0.1 \%$ Tween 20 , pH 7.5), run in duplicate. A standard concentration curve, consisting of urinary human RBP antigen (Biogenesis, Kingston, NH, USA) diluted in PBS with $0.1 \%$ Tween $20, \mathrm{pH} 7.5$, to give concentrations of $0.244-1.95 \mathrm{ng} / \mathrm{ml}$, was also included on each plate. After overnight incubation at $4^{\circ} \mathrm{C}$, plates were washed as described above and rabbit antihuman RBP conjugated to horseradish peroxidase (Dako Corp., Carpinteria, CA, USA), diluted 3000fold in PBS with $0.1 \%$ Tween 20, pH 7.5, was added ( $100 \mu \mathrm{l}$ per well). After two hours at room temperature, plates were washed and $100 \mu \mathrm{l}$ per well of $7.4 \mathrm{mmol} / \mathrm{l}$ o-phenylenediamine (Sigma-Aldrich Corporation, St Louis, MO, USA), $5.9 \mathrm{mmol} / \mathrm{l}$ hydrogen peroxide in $72 \mathrm{mmol} / \mathrm{l}$ phosphate-27 mmol/l citrate in $0.1 \%$ Tween 20 buffer, $\mathrm{pH}$ 6.0, was added. After 20 minutes at room temperature, $50 \mu \mathrm{l}$ per well of $2 \mathrm{M}$ sulphuric acid was added. The absorbance was measured at $490 \mathrm{~nm}$ with a MAXline microplate reader (Molecular Devices, Sunnyvale, CA, USA). RBP concentrations were calculated from the standard curve on each plate. Samples were repeated if CVs were $>10 \%$ 

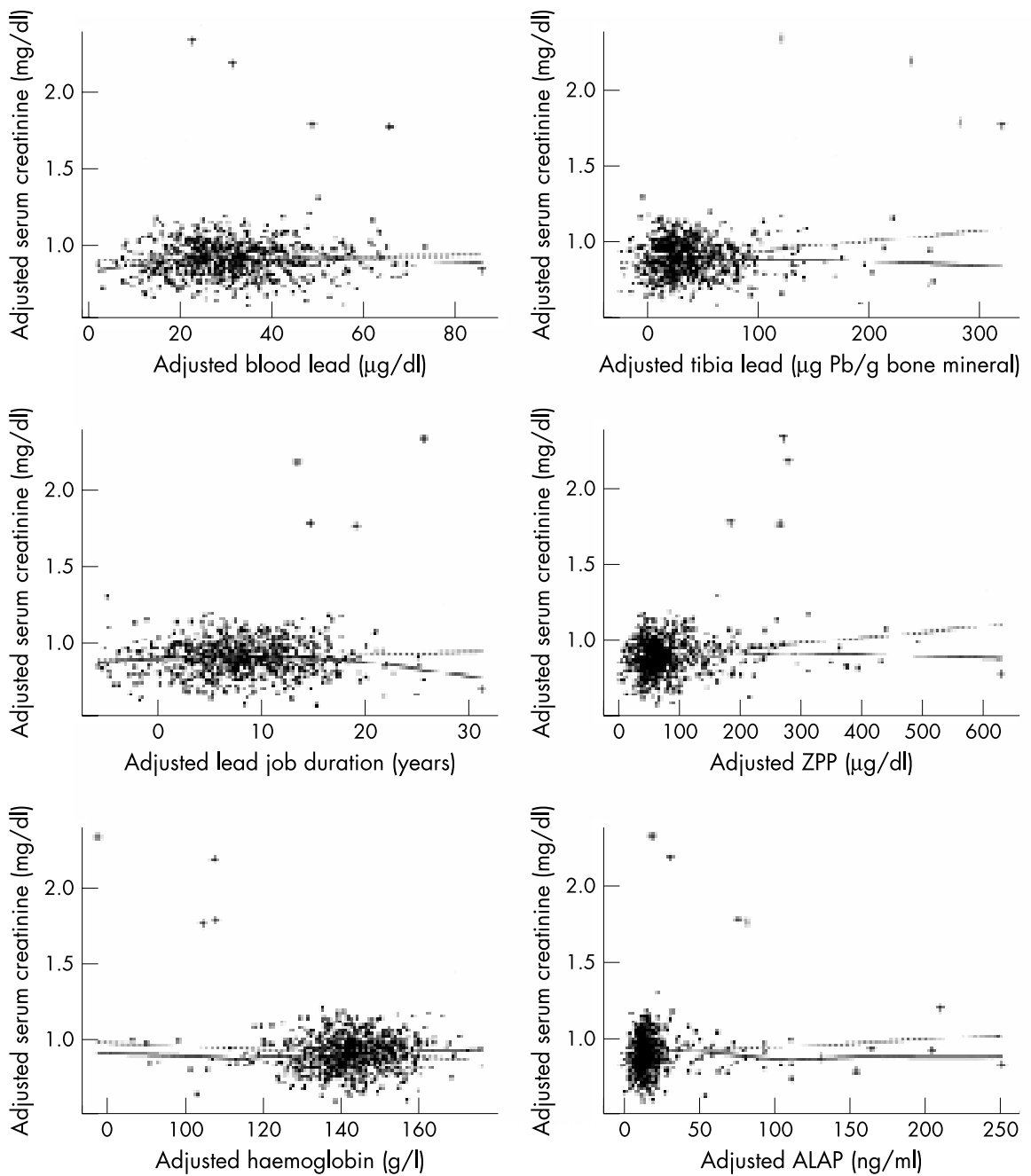

Figure 1 Associations (added variable plots) of serum creatinine with six lead measures in 803 Korean lead workers. The dotted line is the adjusted regression line; the solid line was estimated by a smoothing method using the S-PLUS statistical software function lowess. Both have been adjusted for covariates. For ease of interpretation, axes have been scaled, so that the plotted residuals are centred around the means, rather than zero. Outliers that were removed in subsequent models are denoted by plus signs.

( $15 \%$ for low samples) and rediluted for absorbances above or below set reproducible levels. To evaluate assay reliability, 75 random samples $(8 \%)$ were measured in duplicate; mean inter-assay, between day CV was $7.4 \%$ (SD 5.2\%).

$\mathrm{Hb}$ was assayed by the cyanmethaemoglobin method (Beckman Coulter, Inc., Model Ac-T 8, Fullerton, CA, USA). ZPP levels were measured with a portable haematofluorimeter (Aviv, Lakewood, NJ, USA)..$^{39}$ ALAP was measured by a high performance liquid chromatography method based on Oishi and colleagues ${ }^{40}$ and Sithisarankul and colleagues. ${ }^{41}$

\section{Statistical analysis}

The primary goals of the analysis were: (1) to compare six renal outcomes (BUN, serum creatinine, measured creatinine clearance, calculated creatinine clearance, RBP, and NAG) in lead workers and controls, while controlling for covariates; and (2) to compare one lead exposure measure (job duration), three lead dose biomarkers (tibia lead, blood lead, DMSA chelatable lead), and three haematologic system effect markers (ALAP, Hb, ZPP) as predictors of those renal outcomes in lead workers, also controlling for covariates. Statistical analysis was completed using software programs of the SAS Institute, Inc. (Cary, NC, USA).

Initially, variable distributions were examined. The distributions of NAG and RBP evidenced departures from normality and were thus log transformed, resulting in approximation of normality for RBP and normality for NAG. Non-normal independent variables were log transformed for testing mean differences between groups (that is, all lead workers versus controls). Next, crude proportions and means of various demographic, exposure, and non-renal outcome measures were compared between groups. Associations of dichotomous variables were evaluated in $2 \times 2$ tables using $\chi^{2}$ or Fisher's exact tests, and continuous variables were compared using $t$ statistics. Linear regression modelling with a dichotomous exposure variable (all lead workers versus controls) was used to compare renal outcome measures by group while controlling for the same covariates used in the final models (see below).

Linear regression modelling was used to evaluate associations between lead measures and renal outcomes in lead exposed participants only and subsets thereof. Covariate selection for final regression models utilised both a priori variables (age, gender, and BMI (weight in $\mathrm{kg}$ divided by the square of height in metres)) as well as biologically directed stepwise forward modelling to determine other significant variables. Covariates tested included diabetes (DM) and hypertension (both based on participant report of physician diagnosis), use of analgesics (based on questionnaire data on medication usage), systolic and diastolic blood pressure, tobacco and alcohol consumption, work status (current versus former worker), and CdU. Covariates in the model for clinical renal outcomes (BUN, serum creatinine, creatinine clearance, 

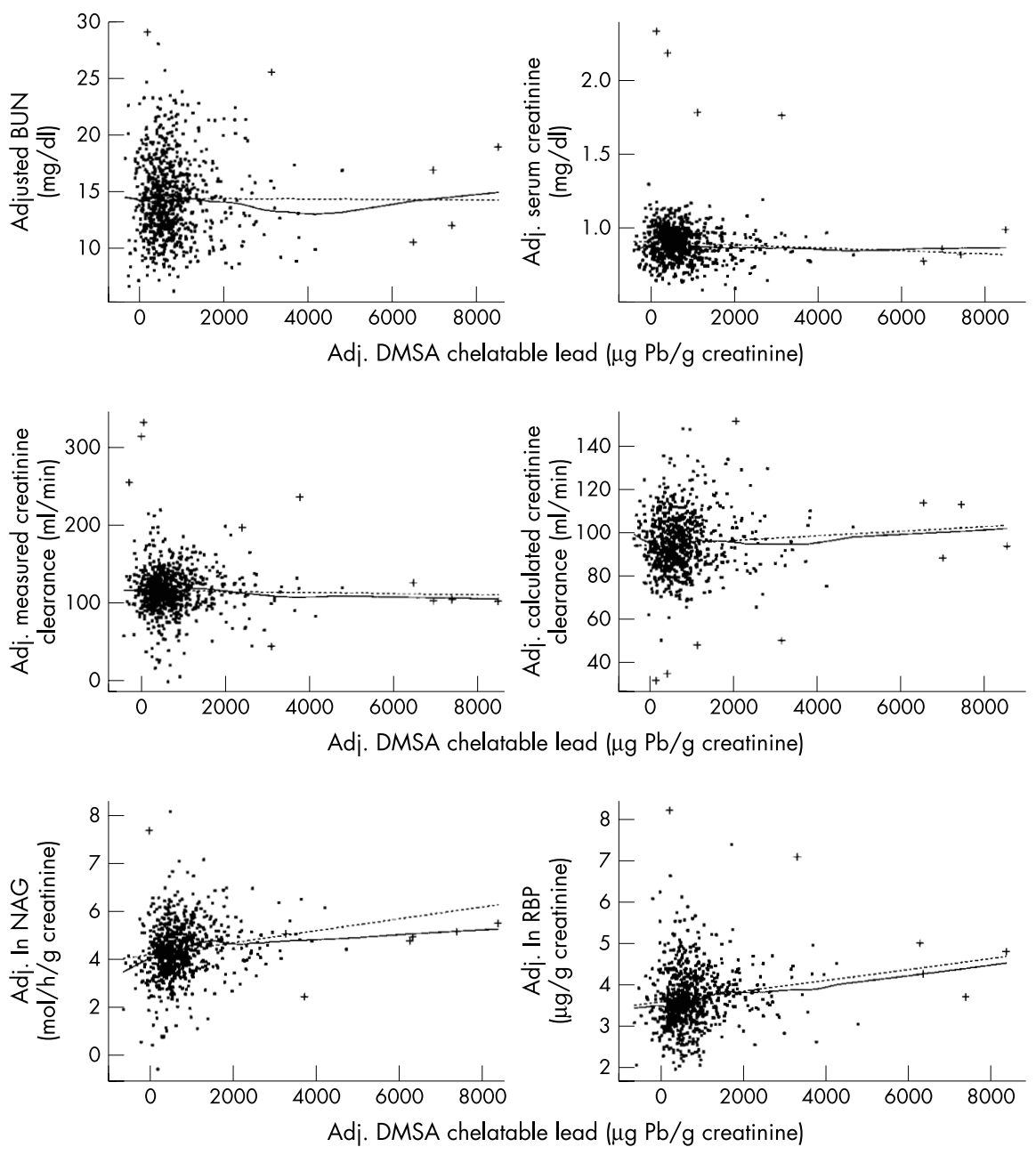

Figure 2 Associations (added variable plots) of DMSA chelatable lead with six renal outcomes in 803 Korean lead workers. The dotted line is the adjusted regression line; the solid line was estimated by a smoothing method using the S-PLUS statistical software function lowess. Both have been adjusted for covariates. For ease of interpretation, axes have been scaled, so that the plotted residuals are centred around the means, rather than zero. Outliers that were removed in subsequent models are denoted by plus signs.

and calculated creatinine clearance) included age, gender, BMI, work status (current versus former worker), and hypertension. NAG and RBP were analysed in models that adjusted for age, gender, BMI, systolic blood pressure, work status, current alcohol use, and DM. Continuous independent variables were centred at the mean or, in the case of the effect modification models discussed below, at the tertile cut point nearest the mean.

Models were evaluated for linear regression assumptions and the presence of outlying points using jackknife residual ${ }^{42}$ and added variable plots. ${ }^{43}$ The latter plots are graphical summaries of the relation between $\mathrm{Y}$ and a particular X (referred to as $\mathrm{X}_{\mathrm{a}}$ below) adjusted for all the other covariates. ${ }^{43}$ Specifically, the residuals of the regression of $Y$ on all the covariates except $\mathrm{X}_{\mathrm{a}}$ are plotted on the $\mathrm{Y}$ axis. This is the part of $\mathrm{Y}$ not explained by those covariates. Next the residuals from the regression of $X_{a}$ on all the other covariates is computed. This is the part of $X_{a}$ not explained by the other covariates. These residuals are plotted on the $\mathrm{x}$ axis. For each plot, two lines were overlaid: the regression line, and a line determined by a scatter plot smoothing method that calculates a locally weighted least squares estimate for each point in the scatter plot. ${ }^{44}$ This allows an examination of the data for outliers that are overly influential as evidenced by inconsistency between the lowess and regression lines. The function "lowess" of the S-plus statistical software program was used to produce the plot (Data Analysis Products Division of MathSoft, Seattle, WA, USA). When applicable, models were repeated without outliers.
Finally, models with cross product terms of the lead measures and age divided into tertiles were evaluated in order to assess whether age modified relations between lead measures and renal outcomes. In order to avoid residual age confounding, centred continuous age was entered as an independent variable instead of the categorical age variables used in the cross product terms.

\section{RESULTS}

Demographics, exposure, and health outcome measures in lead workers and controls

Compared to controls, lead exposed participants were significantly $(\mathrm{p}<0.05)$ older, had a higher proportion of female participants, and lower mean BMI (table 1). There was a wide range of blood lead, tibia lead, and DMSA chelatable lead levels among lead workers; mean blood lead and tibia lead were significantly higher than in control participants. CdU levels were generally consistent with non-occupational exposure; all were $\leqslant 3 \mu \mathrm{g} / \mathrm{g}$ creatinine, with the exception of four values ( $2.1 \%$ ) between 3 and $4 \mu \mathrm{g} / \mathrm{g}$ creatinine and one outlier of 7.3 $\mu \mathrm{g} / \mathrm{g}$ creatinine. The Spearman rank correlation coefficients for CdU with tibia lead, blood lead, DMSA chelatable lead, job duration, and age were $0.29,0.13,0.34,0.33$, and 0.61 respectively $(p=0.0001$ for all except blood lead, for which $\mathrm{p}=0.08)$. However, multiple linear regression modelling showed that cadmium was not significantly associated with any of the four lead variables when age was entered into the 
Table 2 Linear regression modelling of renal outcomes with lead dose biomarkers, lead job duration, and haematopoietic effect biomarkers in all lead workers with outliers removed*

\begin{tabular}{|c|c|c|c|c|}
\hline Lead variable & $\beta$ coefficient & SE $\beta$ & $\mathrm{p}$ value & Model $r^{2}$ \\
\hline \multicolumn{5}{|l|}{ BUN (mg/dl) models } \\
\hline Tibia lead, jg $\mathrm{Pb} / \mathrm{g}$ bone mineral & -0.0010 & 0.0035 & 0.78 & 0.08 \\
\hline Blood lead, $\mu \mathrm{g} / \mathrm{dl}$ & 0.0017 & 0.0099 & 0.86 & 0.08 \\
\hline DMSA chelatable lead, $\mu \mathrm{g} \mathrm{Pb} / \mathrm{g}$ creatinine & -0.0001 & 0.0002 & 0.50 & 0.09 \\
\hline Lead job duration, years & 0.0014 & 0.0232 & 0.95 & 0.08 \\
\hline ALAP, $\mathrm{ng} / \mathrm{ml}$ & 0.0167 & 0.0091 & 0.07 & 0.09 \\
\hline $\mathrm{ZPP}, \mu \mathrm{g} / \mathrm{dl}$ & 0.0039 & 0.0022 & 0.07 & 0.09 \\
\hline Haemoglobin, $\mathrm{g} / \mathrm{dl}$ & -0.2357 & 0.1119 & 0.04 & 0.09 \\
\hline \multicolumn{5}{|l|}{ Serum creatinine $(\mathrm{mg} / \mathrm{dl})$ models } \\
\hline Tibia lead, $\mu \mathrm{g} \mathrm{Pb/g}$ bone mineral & -0.0002 & 0.0001 & 0.17 & 0.36 \\
\hline Blood lead, $\mu \mathrm{g} / \mathrm{dl}$ & 0.0001 & 0.0003 & 0.85 & 0.36 \\
\hline DMSA chelatable lead, $\mu \mathrm{g} \mathrm{Pb} / \mathrm{g}$ creatinine & -0.0000 & 0.0000 & $<0.01$ & 0.36 \\
\hline Lead job duration, years & -0.0006 & 0.0007 & 0.41 & 0.36 \\
\hline $\mathrm{ALAP}, \mathrm{ng} / \mathrm{ml}$ & 0.0001 & 0.0003 & 0.81 & 0.36 \\
\hline $\mathrm{ZPP}, \mu \mathrm{g} / \mathrm{dl}$ & 0.0001 & 0.0001 & 0.05 & 0.36 \\
\hline Haemoglobin, $g / d l$ & 0.0095 & 0.0035 & $<0.01$ & 0.36 \\
\hline \multicolumn{5}{|l|}{ Measured creatinine clearance $(\mathrm{ml} / \mathrm{min})$ models } \\
\hline Tibia lead, $\mu \mathrm{g} \mathrm{Pb} / \mathrm{g}$ bone mineral & 0.0608 & 0.0276 & 0.03 & 0.26 \\
\hline Blood lead, $\mu g / d l$ & 0.1079 & 0.0792 & 0.17 & 0.25 \\
\hline DMSA chelatable lead, $\mu \mathrm{g} \mathrm{Pb} / \mathrm{g}$ creatinine & -0.0004 & 0.0015 & 0.78 & 0.25 \\
\hline Lead job duration, years & 0.2499 & 0.1811 & 0.17 & 0.25 \\
\hline ALAP, $\mathrm{ng} / \mathrm{ml}$ & -0.1342 & 0.0753 & 0.08 & 0.25 \\
\hline $\mathrm{ZPP}, \mu \mathrm{g} / \mathrm{dl}$ & -0.0262 & 0.0169 & 0.12 & 0.25 \\
\hline Haemoglobin, $g / d l$ & 0.7858 & 0.8769 & 0.37 & 0.25 \\
\hline \multicolumn{5}{|l|}{ Calculated creatinine clearance $(\mathrm{ml} / \mathrm{min})$ models } \\
\hline Tibia lead, $\mu \mathrm{g} \mathrm{Pb} / \mathrm{g}$ bone mineral & 0.0140 & 0.0133 & 0.29 & 0.60 \\
\hline Blood lead, $\mu \mathrm{g} / \mathrm{dl}$ & -0.0200 & 0.0367 & 0.59 & 0.60 \\
\hline DMSA chelatable lead, $\mu \mathrm{g} \mathrm{Pb} / \mathrm{g}$ creatinine & 0.0010 & 0.0007 & 0.14 & 0.60 \\
\hline Lead job duration, years & 0.1980 & 0.0858 & 0.02 & 0.60 \\
\hline $\mathrm{ALAP}, \mathrm{ng} / \mathrm{ml}$ & -0.0259 & 0.0345 & 0.45 & 0.60 \\
\hline $\mathrm{ZPP}, \mu \mathrm{g} / \mathrm{dl}$ & -0.0125 & 0.0081 & 0.12 & 0.60 \\
\hline Haemoglobin, g/dl & -0.9257 & 0.4222 & 0.03 & 0.61 \\
\hline \multicolumn{5}{|l|}{ In NAG (ln [ $\mu \mathrm{mol} / \mathrm{h} / \mathrm{g}$ creatinine]) models } \\
\hline Tibia lead, $\mu \mathrm{g} \mathrm{Pb} / \mathrm{g}$ bone mineral & 0.0016 & 0.0006 & $<0.01$ & 0.20 \\
\hline Blood lead, $\mu \mathrm{g} / \mathrm{dl}$ & 0.0064 & 0.0016 & $<0.01$ & 0.21 \\
\hline DMSA chelatable lead, $\mu \mathrm{g} \mathrm{Pb/g}$ creatinine & 0.0002 & 0.0000 & $<0.01$ & 0.22 \\
\hline Lead job duration, years & 0.0056 & 0.0038 & 0.14 & 0.19 \\
\hline ALAP, $\mathrm{ng} / \mathrm{ml}$ & 0.0042 & 0.0015 & $<0.01$ & 0.20 \\
\hline $\mathrm{ZPP}, \mathrm{gg} / \mathrm{dl}$ & 0.0010 & 0.0004 & $<0.01$ & 0.20 \\
\hline Haemoglobin, $\mathrm{g} / \mathrm{dl}$ & 0.0026 & 0.0188 & 0.89 & 0.19 \\
\hline \multicolumn{5}{|l|}{ In RBP (ln [ $\mu \mathrm{g} / \mathrm{g}$ creatinine]) models } \\
\hline Tibia lead, $\mu \mathrm{g} \mathrm{Pb} / \mathrm{g}$ bone mineral & 0.0005 & 0.0007 & 0.47 & 0.17 \\
\hline Blood lead, $\mathrm{gg} / \mathrm{dl}$ & 0.0024 & 0.0020 & 0.23 & 0.17 \\
\hline DMSA chelatable lead, $\mu \mathrm{g} \mathrm{Pb} / \mathrm{g}$ creatinine & 0.0001 & 0.0000 & $<0.01$ & 0.17 \\
\hline Lead job duration, years & 0.0056 & 0.0046 & 0.23 & 0.17 \\
\hline $\mathrm{ALAP}, \mathrm{ng} / \mathrm{ml}$ & 0.0056 & 0.0019 & $<0.01$ & 0.18 \\
\hline $\mathrm{ZPP}, \mu \mathrm{g} / \mathrm{dl}$ & 0.0004 & 0.0004 & 0.36 & 0.17 \\
\hline Haemoglobin, g/dl & -0.0324 & 0.0229 & 0.16 & 0.17 \\
\hline \multicolumn{5}{|c|}{$\begin{array}{l}\text { *The renal outcomes were each modelled separately with one of the seven lead measures included at a time } \\
\text { (resulting in a total of } 42 \text { models). Regression results from each model are presented only for the association } \\
\text { of the lead measure with the renal outcome. BUN, serum creatinine, four hour creatinine clearance, and } \\
\text { calculated creatinine clearance models were adjusted for age, gender, BMI, work status (current } v \text { former } \\
\text { worker), and hypertension. NAG and RBP models were adjusted for age, gender, BMI, systolic blood } \\
\text { pressure, work status (current } v \text { former worker), current alcohol ingestion, and diabetes. }\end{array}$} \\
\hline
\end{tabular}

models. Mean values of the renal outcome measures indicated worse function in exposed participants compared to controls for four outcomes; however, after adjustment for covariates, the difference reached statistical significance only for BUN.

\section{Associations of renal outcomes with lead measures in all lead workers}

All renal outcomes except measured creatinine clearance were associated with one or more lead exposure, dose, or haematologic effect (modelled as surrogates for lead exposure) measure in linear regression modeling in all 803 lead workers. Higher lead measures were associated $(\mathrm{p}<0.05)$ with worse renal outcomes in 16 of the 42 models, including nine with NAG or RBP. Borderline associations $(\mathrm{p}<0.1)$ were present in four additional models; two were associated with worse renal outcomes. Tibia lead was associated with BUN, serum creatinine, RBP, and NAG; blood lead was associated only with
NAG. However, when added variable plots of these models were examined, outliers were present (figs 1 and 2). Data from four individuals with renal insufficiency (serum creatinine $>1.5 \mathrm{mg} / \mathrm{dl}$ ) were particularly influential. They included two current and two former workers, three of whom had high lead doses. Three were on antihypertensive medications and three had been diagnosed with renal disease. None were diabetic.

Outliers that were potentially influential for each renal and lead variable were removed from all models in which the variable was present and the models were repeated. This reduced the potential for erroneously leaving influential data points in models although, as shown in fig 2, some data points were removed from models in which they were not influential. However, the maximum number of points removed from any of these models was only 11 (1.4\%). Few differences were observed in associations with the EBE markers; seven of the 10 previous associations remained with little change in the beta 


\begin{tabular}{|c|c|c|c|c|}
\hline Lead variable & $\beta$ coefficient & SE $\beta$ & $\mathrm{p}$ value & Model $r^{2}$ \\
\hline \multicolumn{5}{|l|}{ BUN (mg/dl) models } \\
\hline Haemoglobin, g/dl & -0.2314 & 0.1244 & 0.06 & 0.08 \\
\hline \multicolumn{5}{|l|}{ Serum creatinine $(\mathrm{mg} / \mathrm{dll})$ models } \\
\hline Tibia lead, $\mu \mathrm{g} \mathrm{Pb} / \mathrm{g}$ bone mineral & -0.0002 & 0.0001 & 0.05 & 0.28 \\
\hline DMSA chelatable lead, $\mu \mathrm{g} \mathrm{Pb} / \mathrm{g}$ creatinine & -0.0000 & 0.0000 & $<0.01$ & 0.28 \\
\hline$Z P P, \mu g / d l$ & 0.0002 & 0.0001 & 0.02 & 0.28 \\
\hline Haemoglobin, $\mathrm{g} / \mathrm{dl}$ & 0.0089 & 0.0038 & 0.02 & 0.28 \\
\hline \multicolumn{5}{|l|}{ Measured creatinine clearance $(\mathrm{ml} / \mathrm{min})$ models } \\
\hline Tibia lead, $\mu \mathrm{g} \mathrm{Pb} / \mathrm{g}$ bone mineral & 0.0530 & 0.0303 & 0.08 & 0.21 \\
\hline Lead job duration, years & 0.3989 & 0.1967 & 0.04 & 0.21 \\
\hline $\mathrm{ZPP}, \mu \mathrm{g} / \mathrm{dl}$ & -0.0310 & 0.0182 & 0.09 & 0.20 \\
\hline \multicolumn{5}{|l|}{ Calculated creatinine clearance $(\mathrm{ml} / \mathrm{min})$ models } \\
\hline Tibia lead, $\mu \mathrm{g} \mathrm{Pb} / \mathrm{g}$ bone mineral & 0.0243 & 0.0139 & 0.08 & 0.60 \\
\hline Lead job duration, years & 0.2238 & 0.0903 & 0.01 & 0.60 \\
\hline $\mathrm{ZPP}, \mu \mathrm{g} / \mathrm{dl}$ & -0.0168 & 0.0084 & 0.05 & 0.60 \\
\hline \multicolumn{5}{|l|}{ In NAG (In [umol/h/g creatinine]) models } \\
\hline Tibia lead, $\mu \mathrm{g} \mathrm{Pb} / \mathrm{g}$ bone mineral & 0.0013 & 0.0006 & 0.04 & 0.18 \\
\hline Blood lead, $\mu \mathrm{g} / \mathrm{dl}$ & 0.0050 & 0.0017 & $<0.01$ & 0.19 \\
\hline DMSA chelatable lead, $\mu \mathrm{g} \mathrm{Pb} / \mathrm{g}$ creatinine & 0.0002 & 0.0000 & $<0.01$ & 0.20 \\
\hline ALAP, $\mathrm{ng} / \mathrm{ml}$ & 0.0033 & 0.0016 & 0.03 & 0.18 \\
\hline $\mathrm{ZPP}, \mu \mathrm{g} / \mathrm{dl}$ & 0.0009 & 0.0004 & 0.02 & 0.18 \\
\hline \multicolumn{5}{|l|}{ In RBP (In [ $\mathrm{\mu g} / \mathrm{g}$ creatinine]) models } \\
\hline DMSA chelatable lead, $\mu \mathrm{g} \mathrm{Pb} / \mathrm{g}$ creatinine & 0.0001 & 0.0000 & $<0.01$ & 0.16 \\
\hline $\mathrm{ALAP}, \mathrm{ng} / \mathrm{ml}$ & 0.0049 & 0.0019 & 0.01 & 0.17 \\
\hline
\end{tabular}

*The renal outcomes were each modelled separately with one of the seven lead measures included at a time (resulting in a total of 42 models). Regression results from each model are presented only for the association of the lead measure with the renal outcome. Only models in which the lead variable was at least borderline significant $(p<0.1)$ are displayed. BUN, serum creatinine, four hour creatinine clearance, and calculated creatinine clearance models were adjusted for age, gender, BMI, and hypertension. NAG and RBP models were adjusted for age, gender, BMI, systolic blood pressure, current alcohol ingestion, and diabetes.

coefficients for the lead variables (table 2). In contrast, in models of the clinical renal outcomes, only four associations $(\mathrm{p}<0.1)$ were similar. Five associations had not been significant in models that included outliers, and one was significant in both sets of models; however, the sign of the beta coefficient changed. The most striking difference after outlier removal, however, was that higher lead measures were associated with lower serum creatinine and higher creatinine clearance measures in five models. Thus, these associations were in an opposite direction compared to those observed with the EBE markers and with eight of the 10 significant or borderline significant clinical outcomes in models with all 803 participants.

\section{Associations of renal outcomes with lead measures in current workers}

Associations in the subset of 709 current workers were similar to those in all lead workers. Higher NAG and RBP were associated with higher lead measures in models both with and without outliers. In clinical renal outcome models in all current workers, lead measures were associated $(\mathrm{p}<0.05)$ in six of 28; higher lead measures were associated with worse renal function in four. However, after outliers were removed, associations were significant $(p<0.05)$ in seven models and borderline significant $(\mathrm{p}<0.1)$ in an additional four (table 3$)$. Higher lead measures were associated with worse renal function in four and with lower serum creatinine and higher creatinine clearances in seven.

\section{Effect modification by age}

Regression models were next performed in all lead workers to evaluate whether age, divided into tertiles $(\leqslant 36$ years, $36.1-46.0$ years, $>46.0$ years), modified the relations among lead exposure and dose measures and renal outcomes. In models with outliers removed (including two additional outliers identified on added variable plots), evidence of effect modification by age on relations between lead measures and renal outcomes was observed (table 4). Interestingly, in several of the clinical outcome models, associations in the youngest age tertile were in the opposite direction of associations in the oldest age tertile (table 4 and fig 3). Specifically, higher lead measures were associated with worse renal function in older workers, but with lower BUN and serum creatinine in younger workers. These associations were borderline significant $(\mathrm{p}<0.1)$ in the youngest age tertile in two models (table 4$)$. Associations with worse renal function in the oldest age tertile were significant $(p<0.05)$ in three of the clinical outcome models (BUN with blood lead, and serum creatinine with tibia and blood lead) and all four NAG models (determined from additional models in which the oldest age tertile was the reference group). Similar results were observed in analyses in current workers only, although the only significant associations $(\mathrm{p}<0.05)$ between lead exposure and dose measures and clinical renal function were in the youngest age tertile (lower BUN and serum creatinine with higher job duration and tibia lead, respectively).

\section{Associations of renal outcomes with environmental cadmium exposure}

The largest CdU value was an extreme outlier which was removed from further analysis.

In the remaining 190 participants, after adjustment for the same covariates used in the preceding models except lead and work status, CdU was associated only with NAG and RBP $(p<0.05)$. Examination of added variable plots and subsequent reanalysis revealed that the relation with RBP was outlier dependent. Of the lead measures, only tibia lead was significantly associated with NAG $(p<0.05)$ in the cadmium subset (DMSA chelatable lead and lead job duration were borderline associated, $\mathrm{p}<0.1$ ). When $\mathrm{CdU}$ and tibia lead were entered as covariates in the same model, both remained associated with NAG $(p<0.05)$. However, in comparing the effects, a $0.5 \mu \mathrm{g} / \mathrm{g}$ creatinine increase in cadmium had the same effect on NAG as a $66.9 \mu \mathrm{g} \mathrm{Pb} / \mathrm{g}$ bone mineral increase in tibia lead. 
Table 4 Linear regression modelling of renal outcomes with cross product terms for lead dose biomarkers/lead job duration and age in tertiles in all lead workers with outliers removed $\dagger$

\begin{tabular}{|c|c|c|c|}
\hline Variable & $\beta$ coefficient & SE $\beta$ & $\mathrm{p}$ value \\
\hline \multicolumn{4}{|l|}{ BUN (mg/dl) models } \\
\hline Intercept & 14.3380 & 0.1503 & $<0.01$ \\
\hline Age, years & 0.0882 & 0.0140 & $<0.01$ \\
\hline Tibia lead, $\mu \mathrm{g} \mathrm{Pb} / \mathrm{g}$ bone mineral & -0.0103 & 0.0085 & 0.23 \\
\hline Tibia lead* ${ }^{*}$ gecat 2 & -0.0021 & 0.0107 & 0.85 \\
\hline Tibia lead*agecat3 & 0.0165 & 0.0096 & 0.09 \\
\hline Intercept & 14.3530 & 0.1509 & $<0.01$ \\
\hline Age, years & 0.0783 & 0.0145 & $<0.01$ \\
\hline Blood lead, pg/dl & -0.0218 & 0.0157 & 0.17 \\
\hline Blood lead*agecat2 & 0.0091 & 0.0223 & 0.68 \\
\hline Blood lead*agecat3 & 0.0615 & 0.0214 & $<0.01$ \\
\hline Intercept & 14.4267 & 0.1547 & $<0.01$ \\
\hline Age, years & 0.0890 & 0.0149 & $<0.01$ \\
\hline DMSA chelatable lead, $\mu \mathrm{g} \mathrm{Pb/g}$ creatinine & -0.0002 & 0.0004 & 0.60 \\
\hline DMSA chelatable lead*agecat 2 & -0.0003 & 0.0005 & 0.58 \\
\hline DMSA chelatable lead*agecat3 & 0.0006 & 0.0005 & 0.28 \\
\hline Intercept & 14.1352 & 0.2082 & $<0.01$ \\
\hline Age, years & 0.1078 & 0.0194 & $<0.01$ \\
\hline Lead job duration, years & -0.1199 & 0.0645 & 0.06 \\
\hline Lead job duration *agecat2 & 0.1170 & 0.0776 & 0.13 \\
\hline Lead job duration*agecat3 & 0.1484 & 0.0683 & 0.03 \\
\hline \multicolumn{4}{|l|}{ Serum creatinine $(\mathrm{mg} / \mathrm{dl})$ models } \\
\hline Intercept & 0.9328 & 0.0046 & $<0.01$ \\
\hline Age, years & 0.0005 & 0.0004 & 0.22 \\
\hline Tibia lead, $\mu \mathrm{g} \mathrm{Pb} / \mathrm{g}$ bone mineral & -0.0005 & 0.0003 & 0.06 \\
\hline Tibia lead*agecat2 & -0.0003 & 0.0003 & 0.37 \\
\hline Tibia lead*agecat3 & 0.0008 & 0.0003 & $<0.01$ \\
\hline Intercept & 0.9340 & 0.0046 & $<0.01$ \\
\hline Age, years & 0.0003 & 0.0004 & 0.51 \\
\hline Blood lead, $\mu g / d l$ & -0.0002 & 0.0005 & 0.62 \\
\hline Blood lead*agecat2 & -0.0004 & 0.0007 & 0.56 \\
\hline Blood lead*agecat3 & 0.0013 & 0.0007 & 0.06 \\
\hline Intercept & 0.9351 & 0.0047 & $<0.01$ \\
\hline Age, years & 0.0008 & 0.0005 & 0.09 \\
\hline DMSA chelatable lead, $\mu \mathrm{g} \mathrm{Pb/g}$ creatinine & -0.0000 & 0.0000 & 0.15 \\
\hline DMSA chelatable lead*agecat2 & -0.0000 & 0.0000 & 0.34 \\
\hline DMSA chelatable lead*agecat 3 & 0.0000 & 0.0000 & 0.31 \\
\hline Intercept & 0.9295 & 0.0063 & $<0.01$ \\
\hline Age, years & 0.0011 & 0.0006 & 0.06 \\
\hline Lead job duration, years & -0.0029 & 0.0020 & 0.15 \\
\hline Lead job duration*agecat2 & 0.0022 & 0.0024 & 0.36 \\
\hline Lead job duration *agecat3 & 0.0028 & 0.0021 & 0.18 \\
\hline \multicolumn{4}{|l|}{ Measured creatinine clearance $(\mathrm{ml} / \mathrm{min})$ models } \\
\hline Intercept & 122.8823 & 1.1689 & $<0.01$ \\
\hline Age, years & -0.7016 & 0.1103 & $<0.01$ \\
\hline Tibia lead, $\mu \mathrm{g} \mathrm{Pb/g}$ bone mineral & 0.1057 & 0.0661 & 0.11 \\
\hline Tibia lead*agecat2 & 0.0649 & 0.0837 & 0.44 \\
\hline Tibia lead*agecat3 & -0.1334 & 0.0753 & 0.08 \\
\hline Intercept & 122.1588 & 1.1940 & $<0.01$ \\
\hline Age, years & -0.7388 & 0.1156 & $<0.01$ \\
\hline Blood lead, $\mu g / d l$ & 0.0917 & 0.1242 & 0.46 \\
\hline Blood lead*agecat2 & 0.0539 & 0.1799 & 0.77 \\
\hline Blood lead*agecat3 & 0.0034 & 0.1710 & 0.98 \\
\hline Intercept & 122.7379 & 1.2142 & $<0.01$ \\
\hline Age, years & -0.6909 & 0.1170 & $<0.01$ \\
\hline DMSA chelatable lead, $\mu \mathrm{g} \mathrm{Pb/g}$ creatinine & 0.0022 & 0.0035 & 0.54 \\
\hline DMSA chelatable lead*agecat2 & -0.0038 & 0.0043 & 0.39 \\
\hline DMSA chelatable lead*agecat3 & -0.0021 & 0.0041 & 0.62 \\
\hline Intercept & 122.6602 & 1.6132 & $<0.01$ \\
\hline Age, years & -0.7604 & 0.1531 & $<0.01$ \\
\hline Lead job duration, years & 0.3278 & 0.5060 & 0.52 \\
\hline Lead job duration*agecat2 & 0.5192 & 0.6061 & 0.39 \\
\hline Lead job duration*agecat3 & -0.4382 & 0.5352 & 0.41 \\
\hline \multicolumn{4}{|l|}{ Calculated creatinine clearance $(\mathrm{ml} / \mathrm{min})$ models } \\
\hline Intercept & 101.5733 & 0.5636 & $<0.01$ \\
\hline Age, years & -1.2002 & 0.0525 & $<0.01$ \\
\hline Tibia lead, $\mu \mathrm{g} \mathrm{Pb/g}$ bone mineral & 0.0214 & 0.0320 & 0.50 \\
\hline Tibia lead*agecat2 & 0.0519 & 0.0410 & 0.21 \\
\hline Tibia lead*agecat3 & -0.0481 & 0.0362 & 0.18 \\
\hline
\end{tabular}




\begin{tabular}{|c|c|c|c|}
\hline Variable & $\beta$ coefficient & SE $\beta$ & $p$ value \\
\hline Intercept & 101.4901 & 0.5616 & $<0.01$ \\
\hline Age, years & -1.1891 & 0.0539 & $<0.01$ \\
\hline Blood lead, $\mu g / d l$ & -0.0265 & 0.0584 & 0.65 \\
\hline Blood lead*agecat2 & 0.0526 & 0.0830 & 0.53 \\
\hline Blood lead*agecat3 & -0.0271 & 0.0800 & 0.74 \\
\hline Intercept & 101.5341 & 0.5756 & $<0.01$ \\
\hline Age, years & -1.2315 & 0.0556 & $<0.01$ \\
\hline DMSA chelatable lead, $\mu \mathrm{g} \mathrm{Pb} / \mathrm{g}$ creatinine & 0.0017 & 0.0017 & 0.30 \\
\hline DMSA chelatable lead*agecat2 & 0.0006 & 0.0020 & 0.76 \\
\hline DMSA chelatable lead*agecat3 & -0.0014 & 0.0019 & 0.46 \\
\hline Intercept & 101.8421 & 0.7663 & $<0.01$ \\
\hline Age, years & -1.2920 & 0.0714 & $<0.01$ \\
\hline Lead job duration, years & 0.2908 & 0.2392 & 0.22 \\
\hline Lead job duration*agecat2 & -0.0047 & 0.2881 & 0.99 \\
\hline Lead job duration*agecat3 & -0.1621 & 0.2532 & 0.52 \\
\hline \multicolumn{4}{|l|}{ In NAG (In [umol/h/g creatinine]) models } \\
\hline Intercept & 5.0814 & 0.0438 & $<0.01$ \\
\hline Age, years & 0.0166 & 0.0025 & $<0.01$ \\
\hline Tibia lead, $\mu \mathrm{g} \mathrm{Pb} / \mathrm{g}$ bone mineral & 0.0004 & 0.0014 & 0.75 \\
\hline Tibia lead*agecat2 & 0.0024 & 0.0017 & 0.16 \\
\hline Tibia lead*agecat3 & 0.0017 & 0.0016 & 0.28 \\
\hline Intercept & 5.0769 & 0.0436 & $<0.01$ \\
\hline Age, years & 0.0154 & 0.0026 & $<0.01$ \\
\hline Blood lead, $\mu g / d l$ & 0.0016 & 0.0025 & 0.52 \\
\hline Blood lead*agecat2 & 0.0063 & 0.0036 & 0.08 \\
\hline Blood lead*agecat3 & 0.0089 & 0.0035 & 0.01 \\
\hline Intercept & 5.0857 & 0.0443 & $<0.01$ \\
\hline Age, years & 0.0155 & 0.0026 & $<0.01$ \\
\hline DMSA chelatable lead, $\mu \mathrm{g} \mathrm{Pb} / \mathrm{g}$ creatinine & 0.0000 & 0.0001 & 0.58 \\
\hline DMSA chelatable lead ${ }^{*}$ agecat2 & 0.0002 & 0.0001 & 0.03 \\
\hline DMSA chelatable lead*agecat3 & 0.0002 & 0.0001 & 0.08 \\
\hline Intercept & 5.0778 & 0.0505 & $<0.01$ \\
\hline Age, years & 0.0183 & 0.0033 & $<0.01$ \\
\hline Lead job duration, years & -0.0040 & 0.0106 & 0.71 \\
\hline Lead job duration*agecat2 & -0.0002 & 0.0126 & 0.99 \\
\hline Lead job duration*agecat3 & 0.0169 & 0.0112 & 0.13 \\
\hline \multicolumn{4}{|l|}{ In RBP (In [ $\mu \mathrm{g} / \mathrm{g}$ creatinine]) models } \\
\hline Intercept & 3.4745 & 0.0546 & $<0.01$ \\
\hline Age, years & 0.0185 & 0.0031 & $<0.01$ \\
\hline Tibia lead, $\mu \mathrm{g} \mathrm{Pb} / \mathrm{g}$ bone mineral & 0.0027 & 0.0017 & 0.12 \\
\hline Tibia lead*agecat2 & -0.0015 & 0.0022 & 0.49 \\
\hline Tibia lead*agecat3 & -0.0028 & 0.0020 & 0.15 \\
\hline Intercept & 3.4527 & 0.0545 & $<0.01$ \\
\hline Age, years & 0.0189 & 0.0032 & $<0.01$ \\
\hline Blood lead, $\mu g / d l$ & 0.0044 & 0.0032 & 0.17 \\
\hline Blood lead*agecat2 & -0.0035 & 0.0045 & 0.44 \\
\hline Blood lead*agecat3 & -0.0030 & 0.0043 & 0.49 \\
\hline Intercept & 3.4622 & 0.0548 & $<0.01$ \\
\hline Age, years & 0.0176 & 0.0033 & $<0.01$ \\
\hline DMSA chelatable lead, $\mu \mathrm{g} \mathrm{Pb} / \mathrm{g}$ creatinine & 0.0002 & 0.0001 & 0.03 \\
\hline DMSA chelatable lead*agecat2 & -0.0000 & 0.0001 & 0.80 \\
\hline DMSA chelatable lead*agecat3 & -0.0002 & 0.0001 & 0.14 \\
\hline Intercept & 3.4920 & 0.0626 & $<0.01$ \\
\hline Age, years & 0.0164 & 0.0041 & $<0.01$ \\
\hline Lead job duration, years & 0.0134 & 0.0131 & 0.31 \\
\hline Lead job duration*agecat2 & -0.0095 & 0.0157 & 0.55 \\
\hline Lead job duration*agecat3 & -0.0084 & 0.0138 & 0.55 \\
\hline \multicolumn{4}{|c|}{$\begin{array}{l}\text { †BUN, serum creatinine, measured creatinine clearance, and calculated creatinine clearance models were } \\
\text { also adjusted for age, gender, BMI, current/former exposure status, and hypertension. NAG and RBP model } \\
\text { were adjusted for age, gender, BMI, systolic blood pressure, current/former exposure status, current alcohol } \\
\text { ingestion, and diabetes. The youngest age tertile is the reference. p values for the cross product terms of the } \\
\text { middle or oldest age categories with the lead measures reflect the statistical significance of the difference } \\
\text { between the slopes of the regression line in that age category and the regression line for the youngest age } \\
\text { group. Slopes in the non-reference categories are obtained by adding the beta coefficient of the cross } \\
\text { product term to the beta coefficient for the reference category. }\end{array}$} \\
\hline
\end{tabular}

\section{DISCUSSION}

In this study, we compared associations of seven lead exposure, dose, and haematologic effect measures with six renal outcomes in a large cross sectional study of Korean lead workers and population controls. Mean renal outcome measures indicated worse function in exposed participants compared to controls for four outcomes; after adjustment for confounders, the difference achieved statistical significance only for BUN. In all lead workers, lead measures were associated with renal function in 20 of 42 models $(p<0.1)$; 

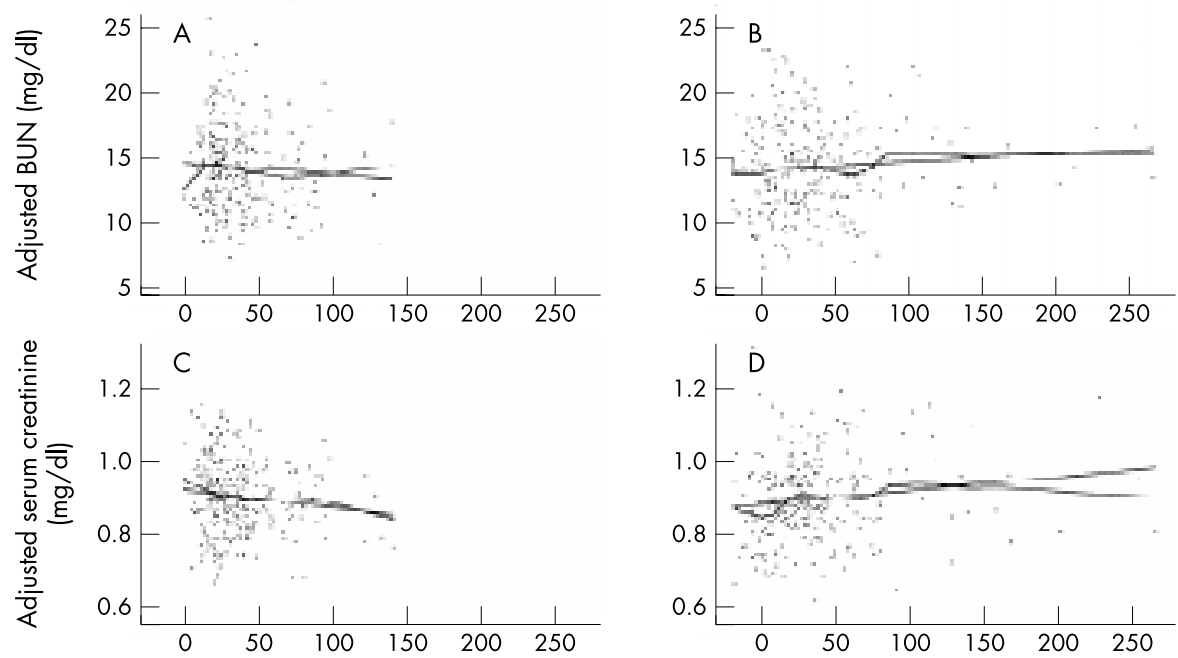

Figure 3 Associations (added variable plots) between renal outcomes and tibia or blood lead in which effect modification by age was observed (803 Korean lead workers with outliers removed). Plots $A, C, E$, $G, I$, and $K$ show relations between lead measures and renal outcomes in participants in the youngest age tertile. Plots $B, D, F, H, J$, and $L$ show these relations in participants in the oldest age tertile. Both the adjusted regression line and the line estimated by the smoothing method of the S-PLUS statistical software function lowess are displayed. Both have been adjusted for covariates. For ease of interpretation, axes have been scaled, so that the plotted residuals are centred around the means, rather than zero.
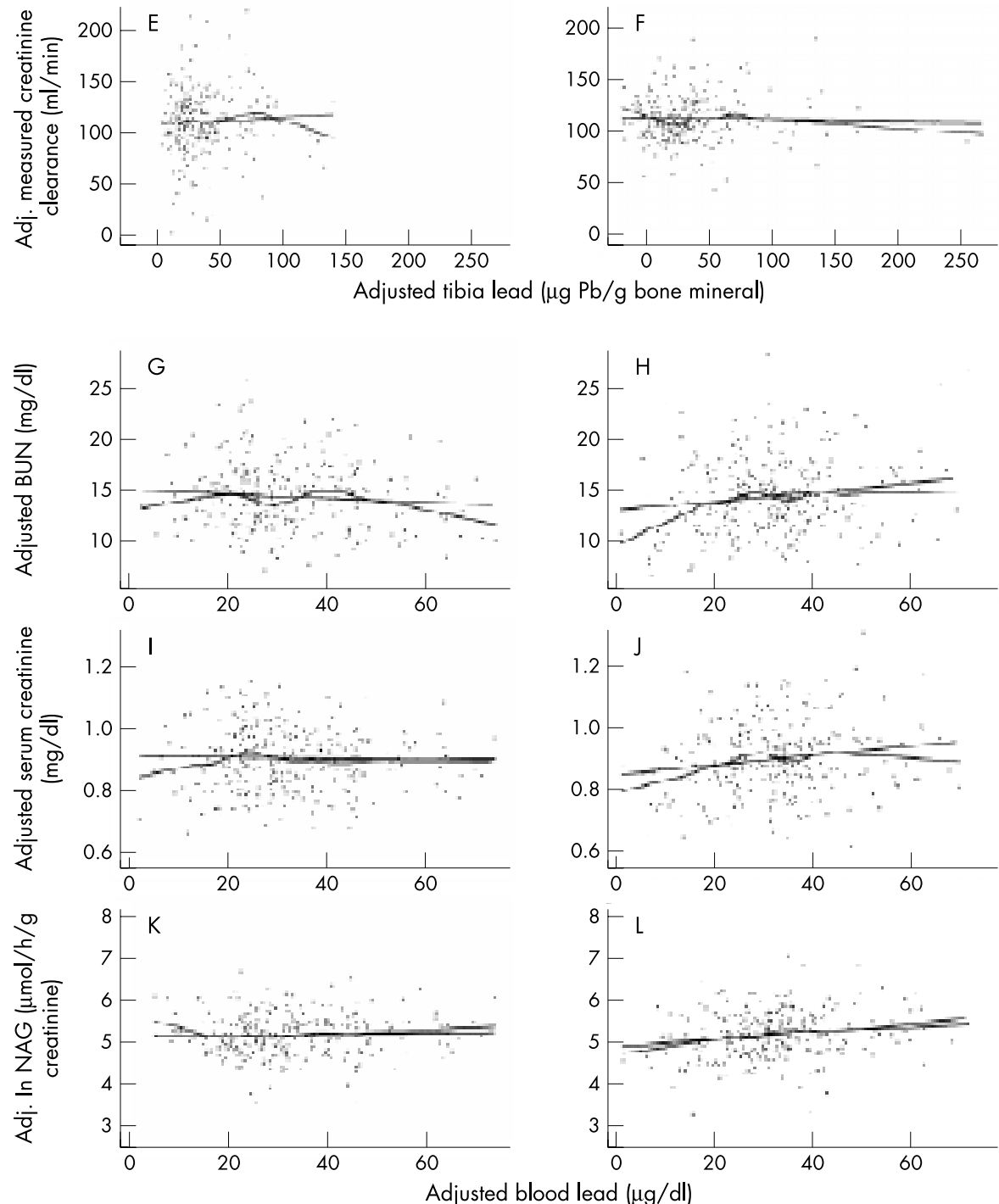

worse renal function was associated with higher lead measures in all but two of these models. However, a few participants with renal insufficiency and high lead dose were extremely influential. When these outliers were removed, 17 associations remained $(p<0.1)$. The relations were relatively unchanged for NAG and RBP. However, for the clinical renal outcomes, five associations between higher lead measures and worse renal function were observed, but an additional five associations were in the opposite direction (higher lead measures associated with lower serum creatinine and higher creatinine clearances).

Models to evaluate the effect modification of age on associations between the lead measures and renal outcomes revealed an intriguing pattern. Associations between higher 
lead measures and worse renal function were observed in participants in the oldest age tertile. In contrast, for the clinical renal outcomes, associations were in the opposite direction in the youngest age tertile. Interestingly, all but one of the clinical outcomes for which these opposite direction associations were observed were not significant in models in which all age groups were combined.

Similar results were obtained when analyses were performed in current workers only, although fewer significant associations between lead measures and worse renal outcomes were observed and, for the clinical outcomes, more significant associations were in the opposite direction.

Associations between increased creatinine clearance and higher lead measures have been previously reported. Mean creatinine clearance in 22 adults who had experienced childhood lead poisoning was significantly increased compared to age and sex matched controls. ${ }^{23}$ A positive association between tibia lead and creatinine clearance was reported in a group of 76 lead workers. ${ }^{21}$ A longitudinal study in rodents reported a positive association between glomerular filtration rate (GFR) and blood lead after three months of exposure to $0.5 \%$ lead acetate in drinking water. ${ }^{45}$ However, after six months of lead ingestion, tubulointerstitial fibrosis was present and, at 12 months, focal glomerulosclerosis was seen and signs of renal insufficiency developed. A similar pattern of renal function change has been observed in human studies of diabetics followed longitudinally; increased creatinine clearance early in the clinical course of diabetes is a predictor of subsequent nephropathy. ${ }^{46}$ Other diseases and conditions in which increased glomerular filtration is present, such as sickle cell disease and obesity, are also associated with an increased risk for subsequent renal abnormalities. ${ }^{47} 48$ The hyperfiltration theory, involving a paradoxical initial increase in GFR associated with glomerular hypertension and ultimately ending in glomerulosclerosis and renal failure, is one mechanistic explanation for this pattern. ${ }^{46}$ However, kidney donors also have raised GFR but generally do not have evidence of other renal abnormalities. These individuals are carefully screened to exclude underlying diseases that could result in adverse renal outcomes which may, in part, explain this observation. ${ }^{48}$ It is also possible that the significance of increased creatinine clearance may vary depending on the underlying condition. The change in direction of associations in our models of the effect modification of age raises the intriguing possibility that lead may cause the same changes in renal function seen in diabetics over time. However, logitudinal studies in lead exposed populations will be necessary to fully understand the prognostic implications of these associations.

In our study, despite low levels, CdU was significantly associated with NAG. Most studies of the associations between lead exposure and renal function have not included cadmium exposure assessment. However, Roels et al reported higher mean NAG in their exposed group. ${ }^{21}$ NAG was not correlated with the lead measures but was correlated with CdU, despite the fact that mean CdU was only $1.04 \mu \mathrm{g} / \mathrm{g}$ creatinine. Cardenas et al reported a similar finding. ${ }^{18}$ Bernard et al found an association between the NAG-B isoenzyme and CdU in cadmium workers, even at levels below $2 \mu \mathrm{g} / \mathrm{g}$ creatinine.$^{49}$ The Cadmibel study, of almost 2000 individuals in the general population of Belgium, found associations between CdU and RBP and NAG $\mathrm{NA}^{50}$, however, creatinine clearance was inversely associated with blood lead and not CdU. ${ }^{6}$ We did not find CdU associations with clinical renal function measures either; however, it was measured in a smaller subset of our population in which fewer associations with lead were observed. The existing data suggest that CdU should be measured in studies of the renal impact of lead, even if cadmium exposure is low.

Lastly, our work identified several factors that may contribute to the inconsistent results in the literature on the renal effects of occupational lead exposure. Associations in opposite directions in different age groups result in lack of significance in models in which those age groups are combined. The age range in occupational studies is truncated and risk for renal disease increases with age. Inclusion of former workers in this study was helpful in this regard. Confounding by environmental cadmium exposure may also account for differences in reported associations between studies, particularly for NAG. Study design issues are another consideration. Our data revealed several associations between renal function and cumulative lead exposure, assessed by tibia lead; however, most studies have measured blood lead only. Finally, clinical renal outcome measures are insensitive to early kidney damage, but there is no commonly accepted renal EBE marker for lead. In our data, in both the entire group of lead workers and the current worker subset, higher lead measures were associated with higher EBE markers; no opposite direction associations were observed. The prognostic value of this is unclear, however, since few longitudinal studies of EBE markers in toxicant exposed populations have been published.

In conclusion, we observed associations between higher lead measures and worse renal function. Associations between higher lead measures and lower BUN and serum creatinine and higher creatinine clearances were also present. In models of effect modification by age, a pattern emerged in which higher lead exposure and dose measures were associated with worse renal function in older workers and the opposite association was observed in younger workers. CdU was also strongly associated with NAG. These data suggest that lead has an adverse effect on renal function in the moderate dose range, particularly in older workers. The significance of associations between higher lead measures and lower BUN and serum creatinine and higher creatinine clearances cannot be determined from a cross sectional study, and may represent lead induced hyperfiltration. Environmental cadmium may also have an adverse renal impact, at least on NAG.

\section{ACKNOWLEDGEMENTS}

We wish to thank Dr Patricia Mueller for providing standards used in setting up the NAG assay and Drs Yong-Bae Kim, Bong-Ki Jang, and Sung-Soo Lee for assisting in data collection in South Korea, and Dr Karen Bandeen-Roche for biostatistical input. This research was supported by grants ES07198 (Dr Schwartz) from the National Institute of Environmental Health Sciences and KRF-2000-00545 (Dr Lee) from the Korea Research Foundation.

\section{Authors' affiliations}

V M Weaver, J Wen, B S Schwartz, Division of Occupational and Environmental Health, Department of Environmental Health Sciences, Johns Hopkins University Bloomberg School of Public Health, Baltimore, Maryland, USA

B-K Lee, K-D Ahn, G-S Lee, Institute of Industrial Medicine, Soonchunhyang University, Chonan, South Korea

A C Todd, Department of Community and Preventive Medicine, Mount Sinai Medical Center, New York, New York, USA

W F Stewart, D J Simon, Department of Epidemiology, Johns Hopkins University Bloomberg School of Public Health

P J Parsons, Lead Poisoning/Trace Elements Laboratory, Wadsworth

Center, New York State Department of Health, Albany, New York, USA

\section{REFERENCES}

1 Steenland K, Selevan S, Landrigan P. The mortality of lead smelter workers: an update. Am J Public Health 1992;82:1641-4.

2 Wedeen RP, Mallik DK, Batuman V. Detection and treatment of occupational lead nephropathy. Arch Intern Med 1979;139:53-7.

3 Inglis JA, Henderson DA, Emmerson BT. The pathology and pathogenesis of chronic lead nephropathy occurring in Queensland. J Pathol 1978;124:65-76.

4 Batuman V. Lead nephropathy, gout, and hypertension. Am J Med Sci 1993;305:241-7.

5 Payton M, Hu H, Sparrow D, et al. Low-level lead exposure and renal function in the Normative Aging Study. Am J Epidemiol 1994; 140:821-9.

6 Staessen JA, Lauwerys RR, Buchet JP, et al. Impairment of renal function with increasing blood lead concentrations in the general population. N Engl J Med 1992;327:151-6. 
$7 \operatorname{Kim} \mathbf{R}$, Rotnitzky A, Sparrow D, et al. A longitudinal study of low-level lead exposure and impairment of renal function. JAMA 1996;275: 1177-81

8 Lin JL, Ho HH, Yu CC. Chelation therapy for patients with elevated body lead burden and progressive renal insufficiency: a randomized, controlled trial. Ann Intern Med 1999;130:7-13.

9 Lin JL, Tan DT, Hsu KH, et al. Environmental lead exposure and progressive renal insufficiency. Arch Intern Med 2001;161:264-71.

10 Ong CN, Endo G, Chia KS, et al. Evaluation of renal function in workers with low blood lead levels. In: Foa V, ed. Occupational and environmental chemical hazards. New York: Halstead Press, 1987:327-33.

11 Cardozo dos Santos A, Colacciopo S, Dal Bo CMR, et al. Occupational exposure to lead, kidney function tests, and blood pressure. Am J Ind Med 1994;26:635-43.

12 Verschoor M, Wibowo A, Herber R, et al. Influence of occupational low-level lead exposure on renal parameters. Am J Ind Med 1987; 12:341-51.

13 Pergande $M$, Jung $K$, Precht $S$, et al. Changed excretion of urinary proteins and enzymes by chronic exposure to lead. Nephrol Dial Transplant 1994;9:613-18.

14 Ramirez-Cervantes B, Embree JW, Hine CH, et al. Health assessment of employees with different body burdens of lead. J Occup Med 1978;20:610-17.

15 Lilis R, Valciukas J, Fischbein A, et al. Renal function impairment in secondary lead smelter workers: correlations with zinc protoporphyrin and blood lead levels. J Environ Pathol Toxicol 1979;2:1447-74.

16 Ehrlich R, Robins T, Jordaan E, et al. Lead absorption and renal dysfunction in a South African battery factory. Occup Environ Med 1998;55:453-60.

17 Omae K, Sakurai H, Higashi T, et al. No adverse effects of lead on renal function in lead-exposed workers. Ind Health 1990;28:77-83.

18 Cardenas A, Roels H, Bernard AM, et al. Markers of early renal changes induced by industrial pollutants. II. Application to workers exposed to lead. Br J Ind Med 1993:50:28-36.

19 Meyer BR, Fischbein A, Rosenman K, et al. Increased urinary enzyme excretion in workers exposed to nephrotoxic chemicals. Am J Med 1984;76:989-98.

20 Gerhardsson L, Chettle DR, Englyst V, et al. Kidney effects in long term exposed lead smelter workers. Br J Ind Med 1992;49:186-92.

21 Roels H, Lauwerys R, Konings J, et al. Renal function and hyperfiltration capacity in lead smelter workers with high bone lead. Occup Environ Med 1994;51:505-12.

22 Roels H, Bernard A, Lauwerys R. Urinary N-acetyl- $\beta$-D-glucosaminidase (NAG) and exposure to inorganic lead. Occup Environ Med 1995;52:286-7.

23 Hu H. A 50-year follow-up of childhood plumbism. Hypertension, renal function, and hemoglobin levels among survivors. Am J Dis Child 1991;145:681-7.

24 Schwartz BS, Lee BK, Lee GS, et al. Associations of blood lead, dimercaptosuccinic acid-chelatable lead, and tibia lead with neurobehavioral test scores in South Korean lead workers. Am J Epidemiol 2001;153:453-64

25 Lee BK, Lee GS, Stewart WF, et al. Associations of blood pressure and hypertension with lead dose measures and polymorphisms in the vitamin $D$ receptor and $\delta$-aminolevulinic acid dehydratase genes. Environ Health Perspect 2001;109:383-9.

26 Kneip TJ, Crable JV. Methods for biological monitoring: a manual for assessing human exposure to hazardous substances. Washington, DC American Public Health Association, 1988: 199-201.

27 Todd AC, McNeill FE. In vivo measurements of lead in bone using a

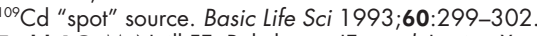

28 Todd AC, McNeill FE, Palethorpe JE, et al. In vivo X-ray fluorescence of lead in bone using $\mathrm{K} X$-ray excitation with ${ }^{109} \mathrm{Cd}$ sources: radiation dosimetry studies. Environ Res 1992;57:117-32.
29 Schwartz BS, Stewart WF, Todd AC, et al. Predictors of dimercaptosuccinic acid chelatable lead and tibial lead in former organolead manufacturing workers. Occup Environ Med 1999;56:22-9.

$30 \mathrm{Kim} \mathbf{R}$, Aro A, Rotnitzky A, et al. K X-ray fluorescence measurements of bone lead concentration: the analysis of low-level data. Phys Med Biol 1995:40: 1475-85.

31 Parsons PJ, Slavin W. Electrothermal atomization atomic absorption spectrometry for the determination of lead in urine: results of an interlaboratory study. Spectrochim Acta Part B 1999;54:853-64.

32 Pruszkowska E, Carnick G, Slavin W. Direct determination of cadmium in urine with use of a stabilized temperature platform furnace and Zeeman background correction. Clin Chem 1983;29:477-80.

33 Hornung RW, Reed LD. Estimation of average concentration in the presence of nondetectable values. Appl Occup Environ Hygiene 1990;5:46-51.

34 Weaver VM, Buckley TJ, Groopman JD. Lack of specificity of trans, trans-muconic acid as a benzene biomarker after ingestion of sorbic acid preserved foods. Cancer Epidemiol Biomarkers Prevention 2000;9:749-55.

35 Cockcroft DW, Gault MH. Prediction of creatinine clearance from serum creatinine. Nephron 1976;16:31-41.

36 Wallach J. Interpretation of diagnostic tests, 6th edn. Boston: Little, Brown and Co. 1996:83

37 Yuen CT, Kind PRN, Price RG, et al. Colorimetric assay for $\mathrm{N}$-acetyl- $\beta$-D-glucosaminidase (NAG) in pathological urine using the $\omega$-nitrostyryl substrate: the development of a kit and the comparison of manual procedure with the automated fluorimetric method. Ann Clin Biochem 1984;21:295-300.

38 Topping MD, Forster HW, Dolman C, et al. Measurement of urinary retinol-binding protein by enzyme-linked immunosorbent assay, and its application to detection of tubular proteinuria. Clin Chem 1986:32:1863-6.

39 Blumberg WE, Eisinger J, Lamola AA, et al. Zinc protoporphyrin level in blood determined by a portable hematofluorometer: a screening device for lead poisoning. J Lab Clin Med 1977;89:712-23.

40 Oishi H, Nomiyama H, Nomiyama K, et al. Fluorometric HPLC determination of delta-aminolevulinic acid (ALA) in the plasma and urine of lead workers: biological indicators of lead exposure. J Anal Toxicol 1996;20:106-10

41 Sithisarankul P, Schwartz BS, Lee BK, et al. Aminolevulinic acid dehydratase genotype mediates plasma levels of the neurotoxin 5-aminolevulinic acid, in lead-exposed workers. Am J Ind Med 1997;32:15-20.

42 Kleinbaum DG, Kupper LL, Muller KE, et al. Applied regression analysis and other multivariable methods, 3rd edn. Pacific Grove, CA: Brooks/Cole Publishing Company, 1998:224-7.

43 Weisberg S. Applied linear regression. New York: John Wiley \& Sons, 1985:52-3.

44 Cleveland WS. Robust locally weighted regression and smoothing scatterplots. J Am Stat Assoc 1979:74:829-36.

45 Khalil-Manesh F, Gonick HC, Cohen AH, et al. Experimental model of lead nephropathy. I. Continuous high-dose lead administration. Kidney Int 1992;41:1192-203

46 Brenner BM, Lawler EV, Mackenzie HS. The hyperfiltration theory: a paradigm shift in nephrology. Kidney Int 1996;49:1774-7.

47 Allon R. Renal abnormalities in sickle cell disease. Arch Intern Med 1990;150:501-4

48 Nenov VD, Taal MW, Sakharova OV, et al. Multi-hit nature of chronic renal disease. Curr Opin Nephrol Hyper 2000;9:85-97.

49 Bernard A, Thielemans N, Roels H, et al. Association between NAG-B and cadmium in urine with no evidence of a threshold. Occup Environ Med 1995;52:177-80.

50 Buchet JP, Lauwerys R, Roels $\mathrm{H}$, et al. Renal effects of cadmium body burden of the general population. Lancet 1990;336:699-702. 